Ramadani L, Heta G, Bekolli L, Rashiti N, Ramabaja Q, Millaku A. The impact of short run distances to the final results of the decathlon at the 2019 Athletic World Championships. Journal of Education, Health and Sport. 2019;9(12):101-109. eISSN 2391-8306. DOI http://dx.doi.org/10.12775/JEHS.2019.09.12.011

https://apcz.umk.pl/czasopisma/index.php/JEHS/article/view/JEHS.2019.09.12.011

https://zenodo.org/record/3596012

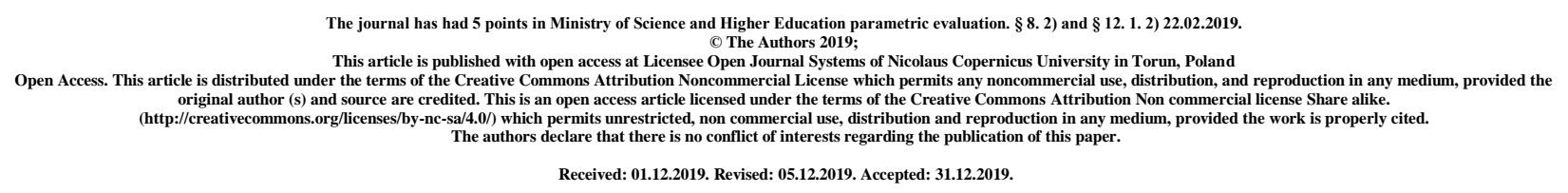

\title{
The impact of short run distances to the final results of the decathlon at the 2019 Athletic World Championships
}

\author{
Ramadani L', Heta G' ${ }^{2}$, Bekolli L ${ }^{3}$, Rashiti ${ }^{3}$, Ramabaja Q4, Millaku A4. \\ Physical education and Sport \\ "Hasan Prishtina" \\ University of Prishtin - Kosova
}

\begin{abstract}
Athletic operates on the basis of a particular system of knowledge that has in its content the theoretical and methodological foundations of sport training (Rashiti N, Nika F, Bekolli L, Heta G.) 2017. Athletic is one of the types of sports, with complex and applicable character, consisting of large groups, which include different athletic types, with similar characteristics among them; our treatment is athletic decathlon.(Dibra F.)2006. The decathlon is a complex combined event in athletic consisting of ten track and field events. Olympic men's decathlons are divided into a two-day competition. The evaluation is done by points. Men's decathlon consists of: 100m, Long jump, Shot put, High jump, 400m (Day 1); 110m hurdles, Discus throw, Pole vault, Javelin throw, $1500 \mathrm{~m}$ (Day 2 ).

The main purpose of this paper was to verify that from the disciplines of the Decathlon: Long jump, Shot put, High jump, Discus throw, Pole vault, Javelin throw and1500m, as predictor (independent) variables will have an impact on the performance of specific motor tasks, respectively the execution of disciplines pertaining to short-distance running: $100 \mathrm{~m}, 110 \mathrm{~m}$ hurdles and 400mas well as to determine the impact of these short-distance running to the final result of the decathlon knowing that these disciplines in athletics are largely genetically determined.(Misja B.) 2012

The sample for the purposes of this paper will include 10 first contestants of decathlons World Championship: September 27 and October 6, 2019 in Doha, Qatar. In this research, after obtaining a statistically significant multiple correlation $(\mathrm{R}=0.936)$ it is necessary to search for the coefficient in the (Beta) column as well as the (t-test) value indicating the influence of each
\end{abstract}


predictor variable (independent) in the dependent or criterion variable $400 \mathrm{~m}$. We can emphasize that the test (F-test) is always more valuable if the multiplex correlation is greater, in this case it is significant $(\mathrm{Sig}=0.000)$, because the value of the F-test is 15,347.A statistically significant multiple correlation was obtained $(\mathrm{R}=0.958)$; it is necessary to search for the coefficient in the (Beta) column as well as the (t-test) value indicating the influence of each predictor (independent) variable in the dependent variable or criterion $110 \mathrm{~m}$.

In this research, after obtaining a statistically significant multiple correlation $(\mathrm{R}=0.958)$, it is necessary to search for the coefficient in the (Beta) column as well as the (t-test) value indicating the influence of each predictor variable (independent) in the dependent or criterion variable) $100 \mathrm{~m}$.

Key words: Decathlon, World Championships, Regression Analysis, Elite Athletes.

\section{METHODS FOR PROCESSING RESULTS}

In order for scientific research to provide a satisfactory solution, it is necessary to use appropriate, right and comparative procedures that are of the nature of this given problem. Considering all these facts, for the purpose of this research the procedures have been selected, to which they are considered and correspond to the nature of the problems being researched.

For each specific motor variable, the following values will be calculated: Basic central and distribution parameters: Minimum and Maximum Values (R.min-R.max), Arithmetic Mean (Ma), Deviation (Ds), and Asymmetry Parameters (SKEW and KURT).

The curve of the distribution or distribution is tested by means of the asymmetry coefficient ("Skewness"), and the degree of curvature of the top of the curve scattered results(distribution height) through the flat coefficient ("'kurtosis").

Relationship ratios between variables in manifest space, as well as correlations between variables system. Regression analysis will be applied to validate the influence of predictor (independent) variables on the criterion(dependent) variables.

\section{PURPOSE OF RESEARCH}

The main purpose of this paper is to prove that the disciplines of the Decathlon: Long jump, Shot put, High jump, Discus throw, Pole vault, Javelin throw and1500m, as predictor (independent) variables will have an impact on the performance of specific motor tasks, respectively the execution of disciplines pertaining to short-distance running: $100 \mathrm{~m}, 110 \mathrm{~m}$ hurdles and $400 \mathrm{~m}$, as well as to determine the impact of these short-distance run to the final results of the decathlon, knowing that these athletic disciplines are largely genetically determined to elite athletes.

The secondary purpose of this paper is: How much of the 100m, 110m hurdles and 400mhave influenced to the final result during 2019. 


\section{SAMPLE OF THE POPULATION}

For the purposes of this paper the sample will include10 first contestants of decathlons World Championship: 2019- London. The results wisll be obtained from the networks and the official website: IAAF - International Association of Athletics Federations | iaaf.org.'

\section{BASIC STATISTICAL PARAMETERS}

In the following text, the basic statistical, asymmetry, and normal distribution parameters for each decathlon discipline applied in this paper will be presented and analyzed according to the order. Table 1 presents the basic statistical characteristics of the applied system of specific motor variables (decathlon): Min values (Min), Max values (Max), Arithmetic mean (Mean), Standard deviation (Std. Dev),Asymmetry parameters (SKEW and KURT) and coefficient of variation $(\mathrm{Kv})$.All distribution variables in Table 1 have normal extension and all variables are homogeneous.

Table 1. Basic statistical parameters of asymmetry and normal distribution of specific variables (decathlon) of the 20 athletes with the best results of the 2019 World Championship

\begin{tabular}{|l|r|r|r|r|r|r|r|r|}
\hline Variables & \multicolumn{1}{c|}{$\mathrm{N}$} & \multicolumn{1}{c|}{ Min } & \multicolumn{1}{c|}{ Max } & \multicolumn{1}{c|}{ Mean } & \multicolumn{1}{l|}{ Std. Dev. } & \multicolumn{1}{l|}{ Skew. } & \multicolumn{1}{l|}{ Kurt } & \multicolumn{1}{l|}{ Kv } \\
\hline VR100M & 10 & 786.00 & 985.00 & 874.80 & 67.44018 & .346 & -.998 & 8.17 \\
\hline KRCGJA & 10 & 767.00 & 925.00 & 886.80 & 49.25173 & -1.890 & 3.684 & 5.79 \\
\hline HEGJYL & 10 & 674.00 & 862.00 & 777.90 & 63.46731 & -.004 & -.946 & 6.97 \\
\hline KRCLAR & 10 & 740.00 & 934.00 & 808.60 & 58.71816 & .866 & 1.180 & 7.42 \\
\hline VR400M & 10 & 753.00 & 959.00 & 865.50 & 67.57095 & -.271 & -.912 & 7.69 \\
\hline V110MP & 10 & 791.00 & 994.00 & 908.40 & 59.65121 & -.543 & .459 & 6.95 \\
\hline HEDISK & 10 & 621.00 & 876.00 & 788.30 & 77.93737 & -1.129 & 1.182 & 6.73 \\
\hline KRCSHK & 10 & 790.00 & 972.00 & 877.00 & 50.50413 & .058 & .795 & 6.11 \\
\hline HESHTI & 10 & 665.00 & 876.00 & 796.00 & 74.75293 & -.557 & -1.113 & 9.26 \\
\hline V1500M & 10 & 645.00 & 846.00 & 738.00 & 70.06663 & .125 & -1.430 & 8.61 \\
\hline Points & 10 & 8158.00 & 8607.00 & 8321.30 & 160.14858 & .800 & -.839 & 1.90 \\
\hline
\end{tabular}

The Relationship and Influence of Specific Motor Variables (Athletic Decathlon Disciplines) in 100m Running (run. 100m)

Through regression analysis in athletes of decathlonin $2019 \mathrm{WCH}$, the value of the relationship between the group of specific motor variables (decathlon disciplines as independent variables and dependent variable (criterion) - 100m run (Run.100m) is obtained. 
Table 2. Regression analysis - the correlation and impact of specific motor variables (athletic decathlon disciplines) in 100m running (Run. 100m)

\begin{tabular}{|l|r|r|r|r|}
\hline Model & \multicolumn{1}{|c|}{$\mathrm{R}$} & R Square & Adjusted R Square & Std. Error of the Estimate \\
\hline 1 & $.958^{\mathrm{a}}$ & .918 & .897 & 21.0449 \\
\hline
\end{tabular}

\begin{tabular}{|l|l|r|r|r|r|r|}
\hline \multicolumn{1}{|l|}{ Model } & Sum of Squares & df & Mean Square & F & \multicolumn{1}{c|}{ Sig. } \\
\hline \multirow{4}{*}{1} & Regression & 153452.908 & 8 & 19181.614 & 43.436 & $.000^{\mathrm{b}}$ \\
\cline { 2 - 8 } & Residual & 13689.867 & 31 & 441.609 & & \\
\cline { 2 - 8 } & Total & 167142.775 & 39 & & & \\
\hline
\end{tabular}

\begin{tabular}{|c|c|c|c|c|c|c|}
\hline \multirow{2}{*}{\multicolumn{2}{|c|}{ Model }} & \multicolumn{2}{|c|}{$\begin{array}{c}\text { Unstandardized } \\
\text { Coefficients }\end{array}$} & \multirow{2}{*}{$\begin{array}{c}\begin{array}{c}\text { Standardized } \\
\text { Coefficients }\end{array} \\
\text { Beta }\end{array}$} & \multirow[t]{2}{*}{$\mathrm{t}$} & \multirow[t]{2}{*}{ Sig. } \\
\hline & & $\mathrm{B}$ & Std. Error & & & \\
\hline \multirow{9}{*}{1} & (Constant) & -451.624 & 185.938 & & -2.429 & .021 \\
\hline & KRCGJA & -.382 & .104 & -.299 & -3.685 & .001 \\
\hline & HEGJYL & -.320 & .126 & -.209 & -2.545 & .016 \\
\hline & KRCLAR & -.327 & .063 & -.274 & -5.211 & .000 \\
\hline & HEDISK & -.221 & .068 & -.248 & -3.254 & .003 \\
\hline & KRCSHK & -.398 & .056 & -.431 & -7.067 & .000 \\
\hline & HESHTI & -.420 & .049 & -.502 & -8.603 & .000 \\
\hline & $\mathrm{V} 1500 \mathrm{M}$ & -.319 & .091 & -.250 & -3.525 & .001 \\
\hline & PIKËT & .392 & .030 & 1.216 & 13.190 & .000 \\
\hline
\end{tabular}

Regression analysis on decathlon athletes indicates that the value of the correlation between the group of independent predictor variables (decathlon athletic variables or disciplines) and the dependent criterion variable - 100m Run (Run. 100m) is obtained.

Correlation of the entire system of independent predictor variables (athletic decathlon disciplines): Long jump, Shot put, High jump, Discus throw, Pole vault, Javelin throw,1500 meters and Total Points (Criteria) and Criterion Dependent Variables - 100 meters Run (Run. $100 \mathrm{~m})$, is confirmed by multiple correlation.

Multiple correlation coefficient has the value $\mathrm{R}=0.958$ which explains the common variability between the predictor variables system and the criterion variable around $91 \%$ ( $\mathrm{R}$ Square $=$ 0.918).

Distribution ( $\mathrm{F}$ is obtained as the distribution of quotient of the two variances, and in these cases it is sometimes necessary to assign the two degrees of freedom. The first degree of freedom is equal to the number of predictor variables $(\mathrm{df}=\mathrm{n})$ respectively $(\mathrm{df}=8)$ and the second is performed so that the number of subjects (40) is reduced by the number of predictor variables minus $1(\mathrm{df}=\mathrm{N})$. $-\mathrm{n}-1)$ respectively $(\mathrm{df}=40-8-1)$.

We can emphasize that the test (F-test) is always more valuable if the multiple correlation is greater, in this case it is significant ( $\mathrm{Sig}=0.000$ ), because the value of the F-test is 43.43.In this research, after obtaining a statistically significant multiple correlation $(\mathrm{R}=0.958)$, it is necessary to search for the coefficient in the (Beta) column as well as the (t-test) value indicating the influence of each predictor variable (independent)) in the dependent or criterion variable).Predictor variables that have an impact on $100 \mathrm{~m}$ running (Run. 100m) are: Long jump(LJ) p $<0.05$, Shot put(ShP) $\mathrm{p}<0.05$, High jump(HJ) $\mathrm{p}<0.05$, Discus throw(DTh) $\mathrm{p}<0.05$, Pole vault(PV) $\mathrm{p}<0.05$,Javelin Throw $(\mathrm{JTh}) \mathrm{p}<0.05,1500$ meters running(Run. $1500 \mathrm{~m}) \mathrm{p}<0.05$ and Total Points(Points) $\mathrm{p}<0.05$. 
The correlation and Influence of Specific Motor Variables (Athletic Decathlon Disciplines) in 400 meters run (Run. 400m)

Through regression analysis on athletes of athletic decathlon in WCH 2019, the correlation value was obtained between the group of specific motor variables (decathlon disciplines) as independent variables and dependent variable (criterion) - 400m Run (Run. 400m).

Table 3. Regression analysis - correlation and impact of specific motor variables (athletic decathlon disciplines) in 400m running (Run. 400m)

\begin{tabular}{|l|r|r|r|r|}
\hline Model & $\mathrm{R}$ & R Square & $\begin{array}{c}\text { Adjusted R } \\
\text { Square }\end{array}$ & $\begin{array}{c}\text { Std. Error of } \\
\text { the Estimate }\end{array}$ \\
\hline 1 & $.936^{2}$ & .877 & .845 & 22.96872 \\
\hline
\end{tabular}

\begin{tabular}{|l|l|r|r|r|c|c|}
\hline \multicolumn{1}{|l|}{ Model } & Sum of Squares & df & Mean Square & F & \multicolumn{1}{c|}{ Sig. } \\
\hline \multirow{3}{*}{1} & Regression & 116593.955 & 8 & 14574.244 & 27.626 & $.000^{\mathrm{b}}$ \\
\cline { 2 - 8 } & Residual & 16354.420 & 31 & 527.562 & & \\
\cline { 2 - 8 } & Total & 132948.375 & 39 & & & \\
\hline
\end{tabular}

\begin{tabular}{|c|c|c|c|c|c|c|}
\hline \multirow{2}{*}{\multicolumn{2}{|c|}{ Model }} & \multicolumn{2}{|c|}{$\begin{array}{c}\text { Unstandardized } \\
\text { Coefficients }\end{array}$} & \multirow{2}{*}{$\begin{array}{c}\text { Standardized } \\
\text { Coefficients } \\
\text { Beta }\end{array}$} & \multirow[t]{2}{*}{$\mathrm{t}$} & \multirow[t]{2}{*}{ Sig. } \\
\hline & & $\mathrm{B}$ & Std. Error & & & \\
\hline \multirow{9}{*}{1} & (Constant) & -121.619 & 203.230 & & -.598 & .554 \\
\hline & KRCGJA & -.140 & .113 & -.123 & -1.237 & .225 \\
\hline & HEGJYL & -.288 & .137 & -.211 & -2.097 & .044 \\
\hline & KRCLAR & -.342 & .069 & -.321 & -4.992 & .000 \\
\hline & HEDISK & -.342 & .074 & -.430 & -4.592 & .000 \\
\hline & KRCSHK & -.212 & .062 & -.258 & -3.454 & .002 \\
\hline & HESHTI & -.240 & .053 & -.322 & -4.503 & .000 \\
\hline & $\mathrm{V} 1500 \mathrm{M}$ & -.037 & .099 & -.032 & -.369 & .714 \\
\hline & PIKËT & .274 & .032 & .954 & 8.444 & .000 \\
\hline
\end{tabular}

Regression analysis on decathlon athletes shows that the value of the correlation between the group of independent predictor variables (decathlon athletic variables or disciplines) and the dependent criterion variable - 400m Run (Run. 400m) is obtained.

Correlation of the entire system of independent predictor variables (athletic decathlon disciplines): Long jump(LJ),Shot put(ShP),High jump(HJ), Discus throw(DTh), Pole vault(PV),Javelin Throw(JTh),1500 meters run(Run. 1500m) and Total Points(Points) and Criterion Dependent Variables - 400m Run (Run. 400m), is proved by multiple correlation.

Multiple correlation coefficient has the value $\mathrm{R}=0.936$ which explains the common variability between the predictor variables system and the criterion variable around $87 \%$ ( $\mathrm{R}$ Square $=$ 0.877).

Distribution $(\mathrm{F})$ is obtained as the quotient distribution of the two variants, and in these cases it is always necessary to designate the two degrees of freedom. The first degree of freedom is equal to the number of predictor variables $(\mathrm{df}=\mathrm{n})$ respectively $(\mathrm{df}=8)$ and the second is performed so that the number of subjects (20) is reduced by the number of predictor variables minus $1(\mathrm{df}=$ $\mathrm{N})$. - $\mathrm{n}-1)$ respectively $(\mathrm{df}=40-8-1)$.

We can emphasize that the test (F-test) is always more valuable if the multiple correlation is larger, in this case it is significant ( $\mathrm{Sig}=0.000)$, because the value of the F-test is 27.62. 
In this research, after obtaining a statistically significant multiple correlation $(\mathrm{R}=0.936)$, it is necessary to search for the coefficient on the (Beta) column as well as the (t-test) value indicating the influence of each predictor variable (independent) in the dependent or criterion variable. Predictor variables that have an impact on the realization of 400m running (Run. 400m) are: Shot $\operatorname{put}(\mathrm{ShP}) \mathrm{p}<0.05$,High jump(HJ) $\mathrm{p}<0.05$, Discus throw(DTh) $\mathrm{p}<0.05$, Pole vault(PV) $\mathrm{p}<0.05$,Javelin Throw $(\mathbf{J T h}) \mathrm{p}<0.05$, and Total Points (Points) $\mathrm{p}<0.05$.

\section{The Relationship and Impact of Specific Motor Variables (Athletic Decathlon Disciplines) in the realization of $110 \mathrm{~m}$ running (Run. $110 \mathrm{~m}$ )}

Through regression analysis to the decathlon athletes of athleticWCH 2019, of specific motor variables (decathlondisciplines) as independent variables and dependent variable (criterion) $110 \mathrm{~m}$ Run (R. 110m)the correlation value between group is gained.

Table 4. Regression analysis - correlation and impact of specific motor variables (athletic decathlon disciplines) in the realization of $110 \mathrm{~m}$ running (Run. 110m)

\begin{tabular}{|l|r|r|r|r|}
\hline Model & \multicolumn{1}{|c|}{ R } & R Square & Adjusted R Square & Std. Error of the Estimate \\
\hline 1 & $.894^{2}$ & .798 & .746 & 26.13864 \\
\hline
\end{tabular}

\begin{tabular}{|l|l|r|r|r|r|r|}
\hline \multicolumn{2}{|l|}{ Model } & Sum of Squares & df & Mean Square & F & Sig. \\
\hline \multirow{3}{*}{1} & Regression & 83883.520 & 8 & 10485.440 & 15.347 & $.000^{\mathrm{b}}$ \\
\cline { 2 - 8 } & Residual & 21180.080 & 31 & 683.228 & & \\
\cline { 2 - 8 } & Total & 105063.600 & 39 & & & \\
\hline
\end{tabular}

\begin{tabular}{|c|c|c|c|c|c|c|}
\hline \multirow{2}{*}{\multicolumn{2}{|c|}{ Model }} & \multicolumn{2}{|c|}{ Unstandardized Coefficients } & \multirow{2}{*}{$\begin{array}{c}\begin{array}{c}\text { Standardized } \\
\text { Coefficients }\end{array} \\
\text { Beta } \\
\end{array}$} & \multirow[t]{2}{*}{$\mathrm{t}$} & \multirow[t]{2}{*}{ Sig. } \\
\hline & & B & Std. Error & & & \\
\hline \multirow{9}{*}{1} & (Constant) & 112.084 & 231.277 & & .485 & .631 \\
\hline & KRCGJA & -.564 & .129 & -.557 & -4.373 & .000 \\
\hline & HEGJYL & -.383 & .156 & -.315 & -2.448 & .020 \\
\hline & KRCLAR & -.257 & .078 & \begin{tabular}{|c|}
-.272 \\
\end{tabular} & -3.300 & .002 \\
\hline & HEDISK & -.209 & .085 & -.295 & -2.465 & .019 \\
\hline & KRCSHK & -.313 & .070 & -.428 & -4.475 & .000 \\
\hline & HESHTI & -.324 & .061 & -.487 & -5.328 & .000 \\
\hline & V1500M & -.341 & .113 & -.338 & -3.034 & .005 \\
\hline & PIKËT & .332 & .037 & 1.299 & 8.981 & .000 \\
\hline
\end{tabular}

Regression analysis on decathlon athletes shows that the value of the correlation between the group of independent predictor variables (decathlon athletic variables or disciplines) and the dependent criterion variable - 110m Hurdles(H. 110m) is obtained.

Correlation of the entire system of independent predictor variables (athletic decathlon disciplines):Long jump(LJ),Shot put(ShP),High jump(HJ), Discus throw(DTh),Pole vault(PV),Javelin Throw(JTh), 1500 meters run(R. 1500m) and Total Points(Points) and Criterion Dependent Variable - 110m Hurdles(H. 110m), is proved by multiple correlation.

Multiple correlation coefficient has the value $\mathrm{R}=0.894$ which explains the common variability between the prediction variables system and the criterion variable around $79 \%$ ( $\mathrm{R}$ Square $=$ 0.798). 
Distribution $(\mathrm{F})$ is obtained as the quotient distribution of the two variants, and in these cases it is always necessary to designate the two degrees of freedom. The first degree of freedom is equal to the number of predictor variables $(\mathrm{df}=\mathrm{n})$ respectively $(\mathrm{df}=8)$ and the second is performed so that the number of subjects (20) is reduced by the number of predictor variables minus $1(\mathrm{df}=\mathrm{N}$ $-\mathrm{n}-1)$ respectively $(\mathrm{df}=40-8-1)$.

We can emphasize that the test (F-test) is always more valuable if the multiple correlation is greater, in this case it is significant $(\mathrm{Sig}=0.000)$, because the value of the F-test is 15.347. In this research, after obtaining a statistically significant multiple correlation $(\mathrm{R}=0.958)$, it is necessary to search for the coefficient in the (Beta) column as well as the (t-test) value indicating the influence of each predictor variable (independent)) in the dependent or criterion variable) (Table 8).Predictor variables that have an impact in the realization of $110 \mathrm{~m}$ Hurdles $(\mathrm{H}$. $110 \mathrm{~m})$ are: Long jump(LJ) $\mathrm{p}<0.05$, Shot $\operatorname{put}(\mathrm{ShP}) \quad \mathrm{p}<0.05$, High jump(HJ) $\mathrm{p}<0.05$, Discus throw(DTh) $\mathrm{p}<0.05$,Pole vault(PV) $\mathrm{p}<0.05$,Javelin Throw $(\mathrm{JTh}) \mathrm{p}<0.05,1500$ meters run (Run. $1500 \mathrm{~m}) \mathrm{p}<0.05$ and Total Points(Points) $\mathrm{p}<0.05$.

\section{CONCLUSION}

Decathlon is athletic discipline that involves many disciplines and is one of the disciplines that requires very high physical preparation(Bowerman, Freeman, \& Gambeta, 2012).

The word "ten" means a discipline that involves ten different athletic disciplines, four of which are running races, three jumping and three throwing. When an athlete starts practicing decathlon, he should be prepared to spend his entire life being prepared, as the ten disciplines cannot be mastered in any time. The decathlon athletes should not have weak disciplines as they affect in the end result. First, it is necessary to dedicate to the weaker disciplines, and when a certain result is achieved, move on to the most successful ones. Each discipline is linked to one more, so the order of the training disciplines should be the same as that of the competition.

The results are taken from the electronic networks and the official website:IAAF - International Association of Athletics Federations | iaaf.org. In this research the following athletic decathlon variables were applied: Long jump(LJ),Shot put(ShP),High jump(HJ), Discus throw(DTh),Pole vault(PV),Javelin Throw(JTh),1500 meters run (Run. 1500m) and Total Points(Points), 100m Run (R. 100m), 110m Hurdles (H. 110m) and 400m Run (R. 400).

\section{After processing the results we can conclude that:}

Athletic running, as a set of physical circular character, realizes the displacement in space and time through steps with the lower sides (legs) at high speed. Each type of run has the same technical and biomechanical basics, but with some features of the shape defined by:

- Runner's condition (length of lever, body weight, level of physical and technical preparation, etc.);

- $\quad$ The technical stages of a race (starting momentum, distance running, etc.);

- $\quad$ Size parameters - steps density, their pace and endurance in different running races.

1. We are focused on this to treat athletic decathlon, of the 10 elite World Championship athletes and we have come to a conclusion (ascertainment)that all decathlon variables of the basic parameters in table no. 1. are homogeneous.

2.Specific motor variables in table no. 2. (the disciplines of the decathlon) as independent variable and dependent variable (criterion) - $100 \mathrm{~m}$ run (R. 100m), is confirmed by multiple correlation.Multiple correlation coefficient has the value $\mathrm{R}=0.958$ which explains the common 
variability between the predictor variables system and the criterion variable around 91\% ( $\mathrm{R}$ Square $=0.918)$.

3.Specific motor variables in table no. 3. (the disciplines of the decathlon) as independent variable and dependent variable (criterion) - 400m run (R. $400 \mathrm{~m})$, is confirmed by multiple correlation.Multiple correlation coefficient has the value $\mathrm{R}=0.936$ which explains the common variability between the predictor variables system and the criterion variable around $87 \%$ ( $\mathrm{R}$ Square $=0.877$ ).

4.Specific motor variables in table no. 4 . (the disciplines of the decathlon) as independent variable and dependent variable (criterion) - $110 \mathrm{~m}$ hurdles (H. $110 \mathrm{~m})$, is confirmed by multiple correlation.Multiple correlation coefficient has the value $\mathrm{R}=0.894$ which explains the common variability between the predictor variables system and the criterion variable around $79 \%$ ( $R$ Square $=0.798)$. 


\section{LITERATURE}

1. Rashiti N, Nika F, Bekolli L, Heta G. (2017) Difference Betwen finalists in antopometric parameters and 100 meters running of top athletes, Jurnal of physical activity and sports, Tiranë. 2.Bondarčuk A. P., K. L. Buchancov, S. V. Voznjak, O. Z. Dimitrusenko, V. A. Zaporožov, J. 3.S. Krasnov, J. V. Lusis, L. D. Milašin (1994): Atletska bacanja. Zagrebački atletski savez, Zagreb.

4Ajvazi V.Rashiti N. (2013) Atletska Ajrobia, ZBORNIKE NAUCNIH I STRUCNIH RADOVA "SPORTA I ZDRAVLJE” Tuzla , ISSN 1840-4790

5. Čoh, M. (2001.): Biomehanika atletike; Fakulteta za šport Univerze v Ljubljani, 6.Nika.F,Heta G,Bekolli L, Rashiti N,Licaj O.(2017) Comparison and runing analysis of 1500m games 1960-2012 And world championship 1983- 2013, Jurnal of physical activity and sports Tiranë.

7. Katić R., B. Maleš and Đ. Miletić (2002): Effect of 6-Month Athletic Training on Motor Abilities in Seven-Year-Old Schoolgirls. Collegium Antropologicum. 26 (2002) 2: 533-538. 8.Komi, V. P., A. Mero (1985.): Biomehanical Analysis of Olimpic Javelin Throwers. Human Kinetics, 2: 44-55.

9. Ling C. T. (1989): Psychological states and self-adjustment methods of elite high jumpers. New studies in athletics, 4(4):59-70

10. Rashiti, N. (2011). Prediktivna vrjednost baterije motorocki testova kod tercanje na kratke i srednje staze, "Sport Mont", br. 25-27, str. 260- 265.

11. Otte, B. (1999). Fitt's and Posner's three-stage model of motor skill acquisition as applied to high jump coaching. Track coach, 147, 4703-4704.

12. Perttunen J., H. Kyrolainen, P. V. Komi and A. Heinonen (2000): Biomechanical loading in the triple jump. Journal of sports sciences, 18:363-370.

13. Reid P. (1989): Plyometrics and the High Jump. New studies in athletics, 4(1):67-74

14. Rod W. Fry, A. R. Morton and D. Keast (1991): Overtraining in athletes, Sports medicine, 12(1):32-65.

15. Young W., G. Wilson, C. Byrne (1999): Relationship between strength qualities and performance in standing and run-up vertical jumps. The journal of sports medicine, 39(4):285293

16. William J. Bowerman; William H. Freeman; T.A.C. i Vern Gambetta: (1999). ATLETIKA prvo izdanje. Zagreb.

Correspondence to:

Rashiti Naser, PhD

Physical education and Sport

University of Prishtin - Kosova

Phone: +38349666619

E-mail: naser.rashiti@uni-pr.edu 